\title{
Condições físico-hídricas de Planossolo cultivado com soja em plantio direto e preparo convencional
}

\author{
Pablo Lacerda Ribeiro ${ }^{(1)}$, Adilson Luís Bamberg(2), Diony Alves Reis ${ }^{(3)}$ e Ana Cláudia Barneche de Oliveira(2) \\ (1)Universidade Federal de Pelotas, Campus Universitário, s/no, Caixa postal 354, CEP $96010-900$ Pelotas, RS, Brasil. E-mail: \\ pabloribeirolr@gmail.com (2)Embrapa Clima Temperado, Rodovia BR-392, Km 78, Caixa Postal 403, CEP 96010-971 Pelotas, RS, Brasil. \\ E-mail: adilson.bamberg@embrapa.br, ana.barneche@embrapa.br ${ }^{(3)}$ Instituto Federal de Educação, Ciência e Tecnologia do Rio Grande do \\ Sul, Avenida Osvaldo Aranha, no 540, Juventude da Enologia, CEP 95700-000 Bento Gonçalves, RS, Brasil. E-mail: dionyodin@gmail.com
}

Resumo - O objetivo deste trabalho foi avaliar os efeitos do sistema plantio direto (PD) e do manejo com preparo convencional (PC) sobre atributos físicos e hídricos de um Planossolo Háplico cultivado com soja, em terras baixas do Sul do Brasil. Amostras indeformadas de solo foram coletadas às camadas de $0,00-0,10$, $0,10-0,20$ e $0,20-0,40 \mathrm{~m}$, para a determinação dos atributos físico-hídricos, tendo-se monitorado o potencial mátrico do solo com sensores, ao longo de um ciclo de produção da soja. Os valores de macroporosidade foram menores do que $0,10 \mathrm{~m}^{3} \mathrm{~m}^{-3}$, independentemente do sistema de manejo do solo, o que restringe a possibilidade de cultivo da soja em sequeiro, pelo comprometimento da difusão de gases. Comparado ao PC, o PD promove a microporosidade na camada de $0,00-0,10 \mathrm{~m}$, o que aumenta o conteúdo de água armazenada no solo e a disponibilidade hídrica para a cultura da soja, com reflexos positivos sobre a produtividade da cultura.

Termos para indexação: Glycine max, cultivo mínimo, disponibilidade hídrica, porosidade do solo, terras baixas, várzeas.

\section{Physico-hydric conditions of an Alfisol cultivated with soybean under no-tillage and conventional tillage}

\begin{abstract}
The objective of this work was to evaluate the effects of no-tillage (NT) and conventional tillage (CT) on the physical and hydric properties of an Albaqualf soil cultivated with soybean, in the lowlands of Southern Brazil. Undisturbed soil samples were collected at the $0.00-0.10,0.10-0.20$, and $0.20-0.40-\mathrm{m}$ soil layers, in order to determine soil physicohydric properties, by monitoring the soil matric potential with sensors, over a cycle of soybean production. Macroporosity values were lower than $0.10 \mathrm{~m}^{3} \mathrm{~m}^{-3}$, irrespectively of the soil management system, which restricts the possibility of rainfed soybean cultivation because it affects gas diffusion. In comparison to CT, NT increases microporosity at the $0.00-0.10-\mathrm{m}$ soil layer, which increases soil water content and soil water availability for soybean crop, with positive effects on crop yield.
\end{abstract}

Index terms: Glycine max, minimal tillage, soil water availability, soil porosity, lowlands, floodplains.

\section{Introdução}

No Rio Grande do Sul, há 5,4 milhões de hectares de terras baixas, o que representa $20 \%$ da área total do estado (Parfitt et al., 2014). Nessas áreas, predomina a produção de arroz irrigado, com os seguintes manejos: cultivo mínimo, 74,2\% da área; preparo convencional, 15,7\%; e pré-germinado, 10,1\% (Irga, 2014). Mesmo incipiente, o sistema plantio direto vem ganhando espaço nesse ambiente, em culturas alternativas ao arroz irrigado, o que tem sido associado à expansão da rotação/sucessão de culturas de sequeiro nessas áreas. A adoção de sistemas de produção sustentáveis e conservacionistas, combinados com culturas alternativas dotadas de valor comercial e liquidez, como a soja, pode contribuir para a manutenção da competitividade produtiva nas terras baixas do RS (Vernetti Junior et al., 2009).

Após um longo predomínio do preparo convencional do solo, associado à sucessão arroz-pecuária extensiva de corte, o cultivo mínimo expandiu-se nos últimos anos, uma vez que o preparo antecipado de verão, seguido de pousio de inverno e semeadura direta, reduz os custos do arroz irrigado e facilita o controle de plantas daninhas (Correia et al., 2013). Ainda assim, esse modo de preparo pressupõe o revolvimento anual e integral da camada superficial do solo. Além disso, é comum também a sistematização do terreno, por meio de aplainamento e entaipamento, para facilitar a irrigação e drenagem do arroz (Lima et al., 2009). 
O preparo do solo com mobilização frequente e intensiva, na produção de arroz irrigado, tem mostrado várias limitações que restringem a qualidade física do solo, geralmente associado ao preparo convencional (Bamberg et al., 2009), ao pré-germinado (Lima et al., 2006) e até mesmo ao cultivo mínimo (Munareto et al., 2010). Entre os problemas decorrentes desses modos de preparo do solo, em terras baixas, a formação de camadas compactadas (Pedrotti et al., 2005) e a redução da matéria orgânica do solo (Rosa et al., 2011) são os mais frequentes e preocupantes.

Condições intrínsecas dos solos de terras baixas, como a topografia predominantemente plana, a elevada relação micro/macroporos e a quase nula condutividade hidráulica saturada (Bamberg et al., 2009), somadas à degradação da estrutura do solo relacionada ao manejo, resultam em alagamento periódico (Parfitt et al., 2014).

Para culturas como a da soja, em terras baixas do Rio Grande do Sul, a promoção dos atributos físicos do solo deve não apenas favorecer a drenagem do excedente hídrico, mas também garantir a disponibilidade de água às plantas em períodos críticos, já que a deficiência hídrica durante o período reprodutivo da soja também tem sido verificada no Estado do Rio Grande do Sul, com redução do rendimento de grãos (Matzenauer et al., 2003). Diversos trabalhos realizados nessas condições avaliaram apenas o efeito dos modos de preparo do solo sobre os atributos físicos (Pedrotti et al., 2005; Bamberg et al., 2009; Lima et al., 2009; Munareto et al., 2010), sem considerar seu reflexo sobre as variações da disponibilidade hídrica ao longo do ciclo produtivo. Pressupõe-se que o sistema plantio direto promove os atributos físico-hídricos do solo e que é capaz de atenuar os danos decorrentes de condições climáticas desfavoráveis (Gubiani et al.,
2014), determinantes para o desempenho agronômico da soja em terras baixas.

O objetivo deste trabalho foi avaliar os efeitos dos sistemas plantio direto e de preparo convencional do solo sobre atributos físicos e hídricos de um Planossolo Háplico, cultivado com soja, em terras baixas do Sul do Brasil.

\section{Material e Métodos}

O trabalho foi realizado na Estação Experimental Terras Baixas, da Embrapa Clima Temperado, no Município Capão do Leão, RS, a 3149'647"S, $52^{\circ} 27^{\prime} 4526^{\prime \prime} \mathrm{W}$, e a $20 \mathrm{~m}$ de altitude. O clima da região é do tipo $\mathrm{Cfa}$, subtropical úmido, segundo a classificação de Köppen-Geiger, com médias anuais de temperatura e precipitação pluvial de $17^{\circ} \mathrm{C}$ e $1.400 \mathrm{~mm}$, respectivamente.

O solo da área experimental é classificado como Planossolo Háplico eutrófico típico (Cunha \& Costa, 2013), de textura franco-arenosa (131 $\mathrm{g} \mathrm{kg}^{-1}$ de argila, $314 \mathrm{~g} \mathrm{~kg}^{-1}$ de silte e $554 \mathrm{~g} \mathrm{~kg}^{-1}$ de areia), na camada $0,00-0,40 \mathrm{~m}$. O resultado da análise química das camadas avaliadas encontra-se na Tabela 1 . O cultivo com soja [Glycine max (L.) Merr.] foi realizado na safra 2013/2014.

Os tratamentos consistiram de uma área com sistema plantio direto (PD) e outra com preparo convencional (PC) do solo. Em anos anteriores a 2006, a área sob PD foi manejada em sistema convencional de cultivo de arroz irrigado: uma safra agrícola de arroz, com preparo convencional do solo, seguida de pastejo sobre a resteva (rebrote + plantas espontâneas) do arroz e de pousio por dois anos consecutivos, tendo-se retornado ao cultivo do arroz irrigado no terceiro ano. A área

Tabela 1. Caracterização química de Planossolo cultivado com soja sob plantio direto (PD) e preparo convencional (PC), a diferentes profundidades no solo.

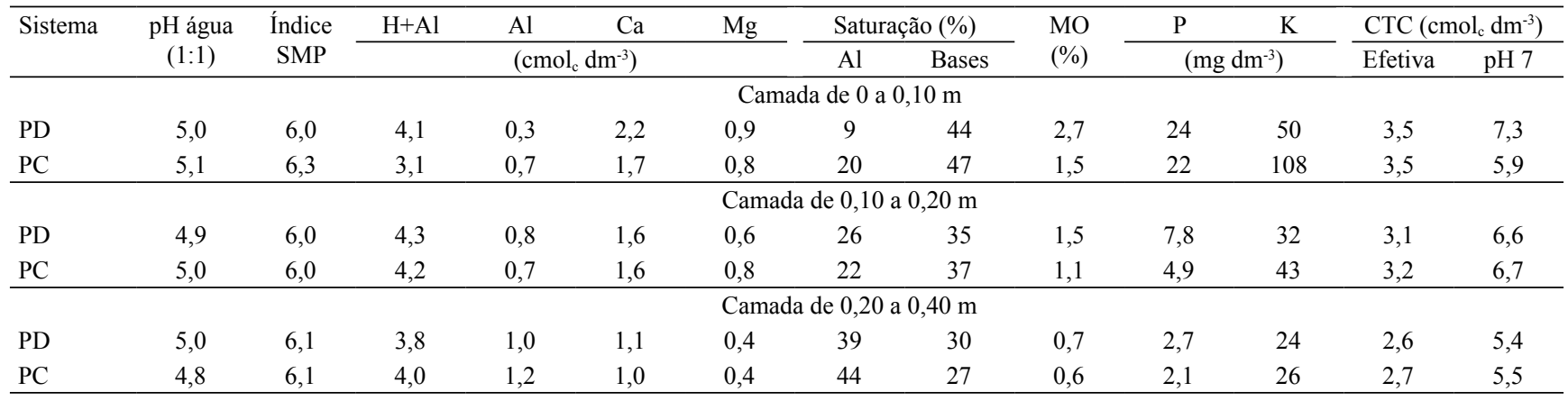


sob PD recebeu a seguinte sucessão de culturas de verão e inverno, nos últimos três anos: milho/azevém/ soja/azevém/soja/azevém. A área sob PC também foi manejada sob sistema convencional de cultivo do arroz irrigado até 2010, tendo permanecido em pousio por três anos, quando, em novembro de 2013, foi preparada (aração e gradagem na profundidade de $0,00-0,20 \mathrm{~m}$ ) e semeada com soja. Neste caso, a sequência de cultivo foi: soja-pousio com manejo das plantas espontâneassoja.

As áreas foram subdivididas em quatro parcelas de $30 \times 5 \mathrm{~m}$, que representaram as repetições. O tráfego de máquinas sobre as parcelas experimentais buscou representar a realidade agrícola atual e ocorreu somente na semeadura e na colheita. As demais operações mecanizadas (pulverizações) foram realizadas com o trator passando sempre em caminhos situados fora das parcelas. A semeadura da cultura da soja foi realizada no dia 28 de novembro de 2013, e a adubação seguiu a recomendação para a cultura, com $300 \mathrm{~kg} \mathrm{ha}^{-1}$ da fórmula 0-25-25 de N-P $\mathrm{O}_{2}-\mathrm{K}_{2} \mathrm{O}$, aplicados à linha de plantio, no momento da semeadura.

As determinações laboratoriais foram realizadas em amostras indeformadas, coletadas aleatoriamente dentro das parcelas, na fase de desenvolvimento vegetativo da cultura, com anéis volumétricos de $0,05 \mathrm{~m}$ de altura e diâmetro, usados no meio das camadas de $0,00-0,10,0,10-0,20$ e $0,20-0,40 \mathrm{~m}$ de profundidade, no total de 72 amostras (3 amostras x 3 camadas $\mathrm{x} 8$ parcelas). Os seguintes atributos físicos do solo foram determinados: Ma, macroporosidade; Mi, microporosidade; Pt, porosidade total; Ds, densidade do solo; CRA, curva de retenção de água no solo; e $\mathrm{AD}$, água disponível às plantas.

Utilizou-se a tensão de $6 \mathrm{kPa}$, para separar a Ma (diâmetro $>0,05 \mathrm{~mm}$ ) da Mi (diâmetro $<0,05 \mathrm{~mm}$ ). A Pt e a Ds foram obtidas pelo método do anel volumétrico (Donagema et al., 2011). Para a determinação da CRA, os anéis foram saturados por capilaridade até atingirem a saturação, e equilibrados às tensões de 1 e $6 \mathrm{kPa}$, em mesa de tensão, e de 10,100 e $300 \mathrm{kPa}$, em câmara de pressão de Richards com placa porosa (Klute, 1986). Além disso, foram determinadas 360 tensões (8 parcelas x 3 camadas x 3 amostras x 5 tensões), nas amostras com estrutura deformada, com psicrômetro (WP4c, Decagon Devices). Essas tensões foram utilizadas para obter o conteúdo volumétrico de água em tensões superiores a $300 \mathrm{kPa}$ (Tabela 2).

A AD $\left(\mathrm{m}^{3} \mathrm{~m}^{-3}\right)$ foi calculada por meio do conteúdo de água à capacidade de campo, à tensão de $10 \mathrm{kPa}$ $\left(\theta_{\mathrm{CC}}\right)$, e por meio do conteúdo de água no ponto de murcha permanente, à tensão de $1.500 \mathrm{kPa}\left(\theta_{\mathrm{PMP}}\right)$, pela expressão $\mathrm{AD}=\left(\theta_{\mathrm{CC}}-\theta_{\mathrm{PMP}}\right)$.

Os dados experimentais de tensão de água vs. conteúdo volumétrico de água, nas amostras de solo, foram ajustados conforme o modelo de Genuchten (1980), com uso do programa MathCAD 2000 (Mathsoft, Cambridge, UK). Para a determinação dos parâmetros de ajuste (Tabela 2) da equação de Genuchten (1980), foram considerados os valores dispostos em Carsel \& Parrish (1988) como iniciais para o processo iterativo, a partir da textura do solo.

Os dados pluviométricos foram obtidos na Estação Agroclimatológica de Pelotas, localizada nas proximidades da área experimental, enquanto a

Tabela 2. Média \pm desvio-padrão dos conteúdos volumétricos de água, discriminados por faixas de tensão de $700-5.000$ a 40.000-80.000 kPa e parâmetros de ajuste $(\theta \mathrm{s}, \theta \mathrm{r}, \alpha, \mathrm{n}, \mathrm{m})$ da equação de Genuchten (1980), em um Planossolo cultivado com soja sob sistema plantio direto (PD) e preparo convencional (PC), a diferentes profundidades no solo.

\begin{tabular}{|c|c|c|c|c|c|c|c|c|c|}
\hline \multirow[t]{2}{*}{ Sistema } & \multicolumn{4}{|c|}{ Conteúdos volumétricos de água $\left(\theta, \mathrm{m}^{3} \mathrm{~m}^{-3}\right)$} & \multirow{2}{*}{$\begin{array}{c}\theta \mathrm{s} \\
\left(\mathrm{m}^{3} \mathrm{~m}^{-3}\right)\end{array}$} & \multirow{2}{*}{$\begin{array}{c}\theta \mathrm{r}^{(1)} \\
\left(\mathrm{m}^{3} \mathrm{~m}^{-3}\right)\end{array}$} & \multirow[t]{2}{*}{$\alpha$} & \multirow[t]{2}{*}{$\mathrm{n}$} & \multirow[t]{2}{*}{$\mathrm{m}$} \\
\hline & $700-5.000$ & $5.000-20.000$ & $20.000-40.000$ & $40.000-80.000$ & & & & & \\
\hline & & \multicolumn{8}{|c|}{ Camada de 0 a $0,10 \mathrm{~m}$} \\
\hline PD & $0,058 \pm 0,035$ & $0,031 \pm 0,014$ & $0,021 \pm 0,008$ & $0,009 \pm 0,002$ & 0,333 & - & 0,001 & 1,550 & 0,355 \\
\hline $\mathrm{PC}$ & $0,055 \pm 0,024$ & $0,034 \pm 0,015$ & $0,023 \pm 0,005$ & $0,012 \pm 0,006$ & 0,319 & - & 0,002 & 1,411 & 0,291 \\
\hline \multicolumn{10}{|c|}{ Camada de 0,10 a $0,20 \mathrm{~m}$} \\
\hline PD & $0,061 \pm 0,032$ & $0,031 \pm 0,007$ & $0,020 \pm 0,001$ & $0,010 \pm 0,004$ & 0,309 & - & 0,002 & 1,395 & 0,283 \\
\hline PC & $0,055 \pm 0,011$ & $0,036 \pm 0,016$ & $0,029 \pm 0,005$ & $0,020 \pm 0,011$ & 0,301 & - & 0,001 & 1,582 & 0,368 \\
\hline \multicolumn{10}{|c|}{ Camada de 0,20 a $0,40 \mathrm{~m}$} \\
\hline PD & $0,042 \pm 0,015$ & $0,023 \pm 0,004$ & $0,017 \pm 0,006$ & $0,010 \pm 0,004$ & 0,293 & - & 0,007 & 1,378 & 0,274 \\
\hline $\mathrm{PC}$ & $0,048 \pm 0,015$ & $0,039 \pm 0,020$ & $0,032 \pm 0,009$ & $0,019 \pm 0,015$ & 0,293 & - & 0,007 & 1,325 & 0,245 \\
\hline
\end{tabular}

(1) Valores $<0,001 \mathrm{~m}^{3} \mathrm{~m}^{-3}$. 
disponibilidade hídrica do solo, na área experimental, foi quantificada com o auxílio de sensores que medem a tensão da água no solo (sensores Watermark, Irrometer), com uso de oito repetições e leituras realizadas semanalmente (três dias por semana), no período de 25 a 134 dias após a semeadura. As leituras cessaram com o término do ciclo de desenvolvimento da soja. As leituras de tensão da água no solo, obtidas em campo, foram inseridas nas equações ajustadas pelo modelo de Genuchten (1980) obtidas das amostras de solo, para definição do conteúdo volumétrico de água do solo $\left(\theta_{\mathrm{CALC}}, \mathrm{m}^{3} \mathrm{~m}^{-3}\right)$. Para o cálculo da água armazenada, em cada data e cada sistema de manejo, utilizou-se a expressão $\mathrm{AA}=\left(\theta_{\mathrm{CALC}} \times \mathrm{E}\right) \times \mathrm{f}$, em que: AA é o volume de água armazenada $\left(\mathrm{m}^{3} \mathrm{ha}^{-1}\right)$; E é a espessura da camada de solo avaliada (m); e f é o fator de conversão para $\mathrm{m}^{3} \mathrm{ha}^{-1}(\mathrm{f}=10.000)$.

Os dados dos atributos físico-hídricos do solo foram avaliados quanto à presença de valores discrepantes e verificados quanto ao ajuste à distribuição normal de probabilidade. Os tratamentos experimentais foram comparados pelo teste $\mathrm{t}$ de Student, a $5 \%$ de probabilidade, com uso do programa Winstat, versão 2.0 (Machado \& Conceição, 2003).

\section{Resultados e Discussão}

Os sistemas de cultivo PD e PC mostraram grande semelhança quanto aos atributos físicos do solo (Tabela 3). Independentemente desse resultado, os tratamentos apresentaram volume poroso aquém do ideal para o desenvolvimento de culturas anuais de sequeiro, sobretudo por terem Ma abaixo de $0,10 \mathrm{~m}^{3} \mathrm{~m}^{-3}$, limite mínimo para a adequada difusão de oxigênio no solo (Reichert et al., 2009). Além disso, esse baixo valor de Ma contribui para a má drenagem da camada superficial. Lima et al. (2006) verificaram valores de Ma próximos de $0,02 \mathrm{~m}^{3} \mathrm{~m}^{-3} \mathrm{em}$ Planossolo, independentemente do manejo adotado.

$\mathrm{O}$ valor crítico de $0,10 \mathrm{~m}^{3} \mathrm{~m}^{-3}$ tem utilidade para fins de comparação; porém, em solos de textura grosseira, a Ma é predominantemente constituída por poros texturais, provenientes do arranjo de partículas elementares do solo (Reichert et al., 2009) que são mal interconectadas e contribuem pouco para as trocas gasosas, o que indica que o limite mínimo de Ma pode ser ainda maior do que $0,10 \mathrm{~m}^{3} \mathrm{~m}^{-3}$. Este fato evidencia a importância da manutenção dos poros estruturais no solo, principalmente dos oriundos da atividade biológica (bioporos), que se destacam por promover a condutividade hidráulica, a aeração e a conexão da superfície com as camadas mais profundas do solo (Lima et al., 2005).

O solo manejado com PD aumentou Mi, na camada de 0,00 a $0,10 \mathrm{~m}$, o que pode ser considerado favorável ao armazenamento de água no solo, essencialmente por elevar a capacidade de retenção de água. Efeitos similares foram relatados em solos sob PD por Lima et al. (2006) e Aratani et al. (2009). As operações do preparo convencional promovem a reorganização da estrutura natural do solo que pode ser reconsolidada durante o período de crescimento da cultura, principalmente com os ciclos de umedecimento e secagem do solo (Bamberg et al., 2011); essa

Tabela 3. Macroporosidade (Ma), microporosidade (Mi), porosidade total (Pt), densidade do solo (Ds) e conteúdo volumétrico de água à capacidade de campo, no ponto de murcha permanente $\left(\theta_{\mathrm{PMP}}\right)$ e na capacidade campo $\left(\theta_{\mathrm{CC}}\right)$, bem como conteúdo de água disponível às plantas (AD), em um Planossolo cultivado com soja, sob plantio direto (PD) e preparo convencional (PC), em diferentes profundidades no solo $^{(1)}$.

\begin{tabular}{|c|c|c|c|c|c|c|c|}
\hline Sistema & Macroporosidade & Microporosidade & Porosidade total & Ds & $\theta_{\mathrm{PMP}}$ & $\theta_{\mathrm{CC}}$ & $\mathrm{AD}$ \\
\hline & 西 & $\left(\mathrm{m}^{3} \mathrm{~m}^{-3}\right)$ & ------------------- & $\left(\mathrm{Mg} \mathrm{m}^{-3}\right)$ & -------- & $\left.{ }^{3} \mathrm{~m}^{-3}\right)$ & -------- \\
\hline & \multicolumn{7}{|c|}{ Camada de 0 a $0,10 \mathrm{~m}$} \\
\hline $\mathrm{PD}$ & $0,06 \mathrm{a}$ & $0,30 \mathrm{a}$ & $0,36 \mathrm{a}$ & $1,53 \mathrm{a}$ & $0,070 \mathrm{a}$ & $0,328 \mathrm{a}$ & $0,258 \mathrm{a}$ \\
\hline \multirow[t]{2}{*}{$\mathrm{PC}$} & $0,07 \mathrm{a}$ & $0,27 \mathrm{~b}$ & $0,34 \mathrm{a}$ & $1,53 \mathrm{a}$ & $0,076 \mathrm{a}$ & $0,301 \mathrm{~b}$ & $0,225 \mathrm{~b}$ \\
\hline & \multicolumn{7}{|c|}{ Camada de 0,10 a $0,20 \mathrm{~m}$} \\
\hline PD & $0,04 \mathrm{a}$ & $0,28 \mathrm{a}$ & $0,32 \mathrm{a}$ & $1,58 \mathrm{a}$ & $0,077 \mathrm{a}$ & $0,297 \mathrm{a}$ & $0,220 \mathrm{a}$ \\
\hline \multirow[t]{2}{*}{$\mathrm{PC}$} & $0,03 \mathrm{a}$ & $0,27 \mathrm{a}$ & $0,30 \mathrm{a}$ & $1,66 \mathrm{a}$ & $0,079 \mathrm{a}$ & $0,297 \mathrm{a}$ & $0,219 \mathrm{a}$ \\
\hline & \multicolumn{7}{|c|}{ Camada de 0,20 a $0,40 \mathrm{~m}$} \\
\hline $\mathrm{PD}$ & $0,05 \mathrm{a}$ & $0,25 \mathrm{a}$ & $0,30 \mathrm{a}$ & $1,60 \mathrm{a}$ & $0,053 \mathrm{a}$ & $0,254 \mathrm{a}$ & $0,202 \mathrm{a}$ \\
\hline $\mathrm{PC}$ & $0,04 \mathrm{a}$ & $0,24 \mathrm{a}$ & $0,29 \mathrm{a}$ & $1,57 \mathrm{a}$ & $0,064 \mathrm{a}$ & $0,258 \mathrm{a}$ & $0,194 \mathrm{a}$ \\
\hline
\end{tabular}

${ }^{(1)}$ Médias seguidas de letras iguais, em uma mesma camada de solo, não diferem pelo teste t de Student, a 5\% de probabilidade. 
reorganização tenderia às condições físicas verificadas no pré-revolvimento (Moret \& Arrúe, 2007). Porém, os microporos podem não ser totalmente recuperados e reconectados, durante a acomodação dos macroporos após a mobilização do Planossolo pelo PC (Lima et al., 2009). Isso provavelmente explica os menores valores médios de Mi no solo sob PC.

A Pt manteve-se igual em todas as camadas avaliadas, inclusive na superfície $(0,00-0,10 \mathrm{~m})$, onde se observou maior Mi no PD. Lima et al. (2008) encontraram resultados semelhantes em Planossolo sob PD e PC. Similarmente ao observado para Pt, a Ds não foi alterada pelos sistemas de cultivo, indício de que o tempo de um ano de implantação de PC, após os três anos de pousio, não foi suficiente para alterar a Ds nesse sistema de manejo, em comparação ao PD, após oito anos da implantação. No entanto, Pedrotti et al. (2005) e Bamberg et al. (2009) relataram maiores valores de Ds no PC, particularmente em camadas superficiais, e atribuíram isto ao intenso tráfego de máquinas (não controlado) e ao revolvimento consecutivo no PC, que teriam compactado as camadas superficiais e reduzido o teor médio de matéria orgânica dos solos (Rosa et al., 2011).

Reichert et al. (2009) sugeriram valores de Ds em torno de $1,70 \mathrm{Mg} \mathrm{m}^{-3}$ como restritivos ao desenvolvimento das plantas, de acordo com o teor de silte + argila do solo. Os valores médios de Ds obtidos no presente estudo não foram superiores a este limite, independentemente do sistema de cultivo.
Não se observaram efeitos do manejo do solo sobre a $\theta_{\text {PMP }}$ (Tabela 3 ), o que provavelmente decorreu do fato de este atributo ser dependente da textura e da mineralogia do solo, que são responsáveis pela retenção de água em altas tensões (Klein et al., 2010), sobretudo quando ocorrem altos teores de argila ou silte + argila e, portanto, se observa pouca ou nenhuma influência do manejo do solo sobre essa variável. Em contrapartida, no solo sob PD, foram observados maiores valores de $\theta_{\mathrm{CC}}$ e do valor médio de $\mathrm{AD}$ (que foi $26 \%$ superior aos observados em PC, na camada de 0,00 a $0,10 \mathrm{~m}$ ). Este resultado pode ser atribuído à maior quantidade de microporos presentes nessa camada, sob PD (Gloaguen et al., 2009).

Em concordância com os valores observados de $\theta_{\mathrm{CC}}$, observou-se maior capacidade de retenção de água a baixas tensões (10 a $300 \mathrm{kPa})$, na camada de 0,00 $0,10 \mathrm{~m}$, no solo sob PD (Figura 1), principalmente à tensão de $100 \mathrm{kPa}$, quando se verificaram retenções de 0,253 e $0,212 \mathrm{~m}^{3} \mathrm{~m}^{-3} \mathrm{em}$ PD e PC, respectivamente. Pereira et al. (2011) relataram maior capacidade de retenção de água nas camadas superficiais de um Latossolo sob PD, em razão da maior microporosidade. Entretanto, observou-se que, com o aumento da profundidade, os valores de CRA entre os manejos tornaram-se mais similares, o que indica que eles não alteraram as condições físico-hídricas nas camadas $0,10-0,20$ e $0,20-0,40 \mathrm{~m}$.

$\mathrm{Na}$ camada de 0,00 a $0,10 \mathrm{~m}$, o conteúdo de água armazenada foi semelhante entre os manejos, logo

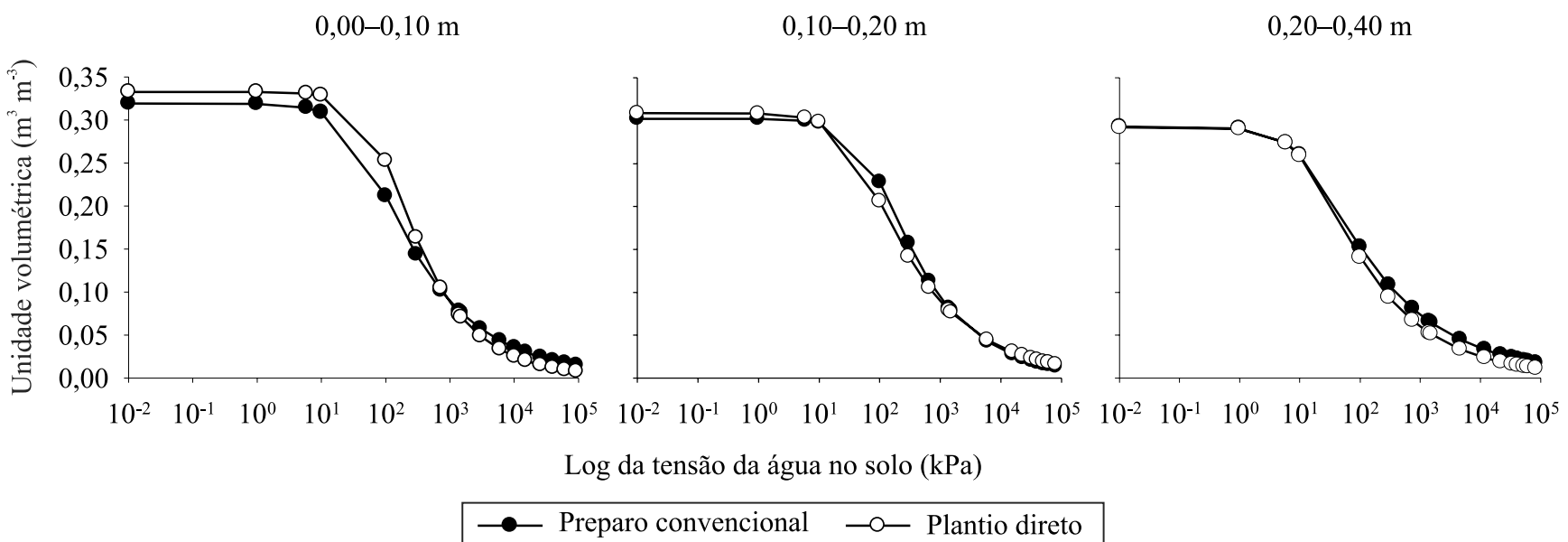

Figura 1. Curvas características de retenção de água, em um Planossolo cultivado com soja em plantio direto (PD) e em preparo convencional (PC), em diferentes profundidades no solo. 
após a ocorrência de chuva (Figura 2). Entretanto, após eventos de precipitação pluvial, o solo sob PC secou mais rapidamente do que o solo sob PD, indício de que, em períodos curtos de estiagem ( $\sim 98-110$ e 112-122 dias após a semeadura), o PD proporciona maior oferta hídrica às raízes superficiais, o que está de acordo com os resultados de Martorano et al. (2009). Além disso, a melhor cobertura do solo proporcionada pelo $\mathrm{PD}$ pode reduzir a perda de água para a atmosfera via evaporação (Odhiambo \& Bomke, 2007), principalmente nas fases iniciais do cultivo, o que favoreceria seu armazenamento no solo. Nas camadas de 0,10 a $0,20 \mathrm{~m}$ e 0,20 a $0,40 \mathrm{~m}$, o conteúdo de água armazenada ao longo do tempo não se diferenciou entre os manejos adotados.
A produtividade de soja, no ciclo produtivo avaliado, foi de $2.969 \pm 459 \mathrm{~kg} \mathrm{ha}^{-1}$, em PD, e de $2.089 \pm 776 \mathrm{~kg} \mathrm{ha}^{-1} \mathrm{em}$ PC. Apesar da alta variabilidade desses dados, constata-se que o cultivo sob PD foi benéfico para a soja. Entretanto, nenhum dos sistemas foi capaz de contornar as limitações da qualidade física dos Planossolos, relacionadas à macroporosidade, apesar de terem diferido quanto ao armazenamento de água no solo. Além disso, cabe salientar a importância da utilização de sistemas eficientes de drenagem superficial, no cultivo de culturas de sequeiro em terras baixas do Sul do Brasil, pois, após períodos de precipitação pluvial e saturação do solo, nenhum dos sistemas de cultivo utilizados foi capaz de mitigar os problemas relacionados ao excedente hídrico.
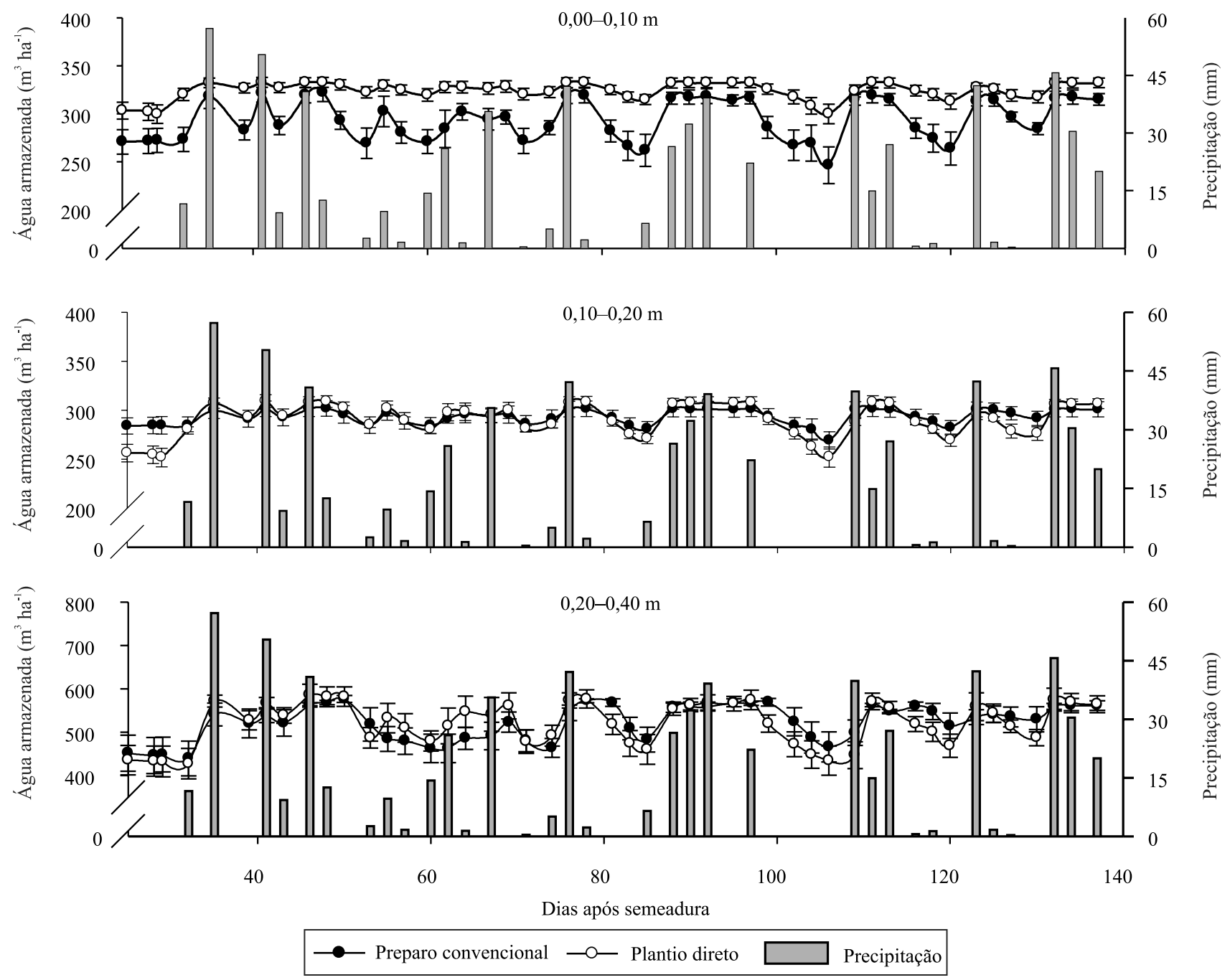

Figura 2. Variação da água armazenada, em um Planossolo cultivado com soja em plantio direto (PD) e preparo convencional (PC), em diferentes profundidades no solo. Barras verticais indicam o desvio-padrão da média. 


\section{Conclusões}

1. A macroporosidade em Planossolo, independentemente do sistema de manejo adotado, é restritiva ao desenvolvimento e crescimento de culturas de sequeiro.

2. O sistema plantio direto promove a microporosidade à profundidade de $0,00 \mathrm{a} 0,10 \mathrm{~m}, \mathrm{o}$ que aumenta o conteúdo de água armazenada no solo e a disponibilidade hídrica para a cultura da soja, com reflexos positivos sobre a produtividade.

\section{Agradecimentos}

Ao Conselho Nacional de Desenvolvimento Científico e Tecnológico (CNPq) e à Fundação de Amparo à Pesquisa do Estado do Rio Grande do Sul (Fapergs), pela concessão de bolsa; à Empresa Brasileira de Pesquisa Agropecuária (Embrapa, projeto no. 02.12.01.016), pelo apoio financeiro.

\section{Referências}

ARATANI, R.G.; FREDDI, O. da S.; CENTURION, J.F.; ANDRIOLI, I. Qualidade física de um Latossolo Vermelho acriférrico sob diferentes sistemas de uso e manejo. Revista Brasileira de Ciência do Solo, v.33, p.677-687, 2009. DOI: 10.1590/S0100-06832009000300020.

BAMBERG, A.L.; CORNELIS, W.M.; TIMM, L.C.; GABRIELS, D.; PAULETTO, E.A.; PINTO, L.F.S. Temporal changes of soil physical and hydraulic properties in strawberry fields. Soil Use and Management, v.27, p.385-394, 2011. DOI: 10.1111/j.14752743.2011.00355.x.

BAMBERG, A.L.; PAULETTO, E.A.; GOMES, A. da S.; TIMM, L.C.; PINTO, L.F.S.; LIMA, A.C.R. de; SILVA, T.R. da. Densidade de um Planossolo sob sistemas de cultivo avaliada por meio da tomografia computadorizada de raios gama. Revista Brasileira de Ciência do Solo, v.33, p.1079-1086, 2009. DOI: 10.1590/S010006832009000500001.

CARSEL, R.F.; PARRISH, R.S. Developing joint probability distributions of soil water retention characteristics. Water Resources Research, v.24, p.755-769, 1988. DOI: 10.1029/ WR024i005p00755.

CORREIA, S. da L.; SILVA, P.R.F. da; SERPA, M. da S.; VIEIRA, V.M.; BOENI, M.; MENEZES, G.B. Estratégias de manejo da palha de azevém para cultivo do arroz irrigado em sucessão. Revista Brasileira de Ciência do Solo, v.37, p.512-520, 2013. DOI: $10.1590 /$ S0100-06832013000200022.

CUNHA, N.G. da; COSTA, F.A. da. Solos da Estação Terras Baixas da Embrapa Clima Temperado. Pelotas: Embrapa Clima Temperado, 2013. 6p. (Embrapa Clima Temperado. Circular técnica, 152).
DONAGEMA, G.K.; CAMPOS, D.V.B. de; CALDERANO, S.B.; TEIXEIRA, W.G.; VIANA, J.H.M. (Org.). Manual de métodos de análise de solo. 2.ed. rev. Rio de Janeiro: Embrapa Solos, 2011. 230p. (Embrapa Solos. Documentos, 132).

GENUCHTEN, M.Th. van. A closed-form equation for predicting the hydraulic conductivity of unsaturated soils. Soil Science Society of America Journal, v.44, p.892-898, 1980. DOI: 10.2136/ sssaj1980.03615995004400050002x.

GLOAGUEN, T.V.; PEREIRA, F.A.C.; GONÇALVES, R.A.B.; PAZ, V. da S. Sistema de extração sequencial da solução na macro e microporosidade do solo. Revista Brasileira de Engenharia Agrícola e Ambiental, v.13, p.544550, 2009.

GUBIANI, P.I.; REICHERT, J.M.; REINERT, D.J. Interação entre disponibilidade de água e compactação do solo no crescimento e na produção de feijoeiro. Revista Brasileira de Ciência do Solo, v.38, p.765-773, 2014. DOI: 10.1590/S0100-06832014000300008.

IRGA. INSTITUTO RIO GRANDENSE DO ARROZ. Safra 2013/14 - amostragem da participação dos sistemas de cultivo. 2014. Disponível em: <http://www.irga.rs.gov.br/ upload/20140225133041sistema_cultivo_13_14_ii.pdf $>$. Acesso em: 6 jul. 2015.

KLEIN, V.A.; BASEGGIO, M.; MADALOSSO, T.; MARCOLIN, C.D. Textura do solo e a estimativa do teor de água no ponto de murcha permanente com psicrômetro. Ciência Rural, v.40, p.1550-1556, 2010.

KLUTE, A. Water retention: laboratory methods. In: KLUTE, A. (Ed.). Methods of soil analysis: part 1: physical and mineralogical methods. $2^{\text {nd }}$ ed. Madison: American Society of Agronomy, Soil Science Society of America, 1986. p.635-660. DOI: 10.2136/ sssabookser5.1.2ed.c26.

LIMA, A.C.R.; HOOGMOED, W.; PAULETTO, E.A.; PINTO, L.F.S. Management systems in irrigated rice affect physical and chemical soil properties. Soil and Tillage Research, v.103, p.9297, 2009. DOI: 10.1016/j.still.2008.09.011.

LIMA, C.L.R. de; PAULETTO, E.A.; GOMES, A. da S.; HARTWIG, M.P.; PASSIANOTO, C.C. Compactação de um Planossolo em função de sistemas de manejo. Revista Brasileira de Agrociência, v.12, p.179-182, 2006.

LIMA, C.L.R. de; PILLON, C.N.; SUZUKI, L.E.A.S.; CRUZ, L.E.C. da. Atributos físicos de um Planossolo Háplico sob sistemas de manejo comparados aos do campo nativo. Revista Brasileira de Ciência do Solo, v.32, p.1849-1855, 2008. DOI: 10.1590 / S0100-06832008000500006.

LIMA, H.V. de; LIMA C.L.R. de; LEÃO, T.P.; COOPER, M.; SILVA, A.P. da; ROMERO, R.E. Tráfego de máquinas agrícolas e alterações de bioporos em área sob pomar de laranja. Revista Brasileira de Ciência do Solo, v.29, p.677-684, 2005. DOI: 10.1590/S0100-06832005000500003.

MACHADO, A.A.; CONCEIÇÃO, A.R. Sistema de análise estatística para Windows - Winstat. Versão 2.0. Pelotas: UFPel, 2003. 42p.

MARTORANO, L.G.; BERGAMASCHI, H.; DALMAGO, G.A.; FARIA, R.T. de; MIELNICZUK, J.; COMIRAN, F. Indicadores 
da condição hídrica do solo com soja em plantio direto e preparo convencional. Revista Brasileira de Engenharia Agrícola e Ambiental, v.13, p.397-405, 2009. DOI: 10.1590/S141543662009000400005.

MATZENAUER, R.; BARNI, N.A.; MALUF, J.R.T. Estimativa do consumo relativo de água para a cultura da soja no Estado do Rio Grande do Sul. Ciência Rural, v.33, p.1013-1019, 2003. DOI: 10.1590/S0103-84782003000600004.

MORET, D.; ARRÚE, J.L. Dynamics of soil hydraulic properties during fallow as affected by tillage. Soil and Tillage Research, v.96, p.103-113, 2007. DOI: 10.1016/j.still.2007.04.003.

MUNARETO, J.D.; BEUTLER, A.N.; RAMÃO, C.J.; DIAS, N.P.; RAMOS, P.V.; POZZEBON, B.C.; ALBERTO, C.M.; HERNANDES, G.C. Propriedades físicas do solo e produtividade de arroz irrigado por inundação no sistema plantio direto. Pesquisa Agropecuária Brasileira, v.45, p.1499-1506, 2010. DOI: 10.1590/ S0100-204X2010001200022.

ODHIAMBO, J.J.O.; BOMKE, A.A. Cover crop effects on spring soil water content and the implications for cover crop management in south coastal British Columbia. Agricultural Water Management, v.88, p.92-98, 2007. DOI: 10.1016/j. agwat.2006.09.001.

PARFITT, J.M.B.; PINTO, M.A.B.; TIMM, L.C. Efeito da sistematização sobre atributos físicos, químicos e biológicos de um solo de várzea no Rio Grande do Sul. Pelotas: Embrapa Clima Temperado, 2014. 30p. (Embrapa Clima Temperado. Boletim de pesquisa e desenvolvimento, 189).
PEDROTTI, A.; PAULETTO, E.A.; CRESTANA, S.; HOLANDA, F.S.R.; CRUVINEL, P.E.; VAZ, C.M.P. Evaluation of bulk density of Albaqualf soil under different tillage systems using the volumetric ring and computerized tomography methods. Soil and Tillage Research, v.80, p.115-123, 2005. DOI: 10.1016/j.still.2004.03.003.

PEREIRA, F. de S.; ANDRIOLI, I.; PEREIRA, F. de S.; OLIVEIRA, P.R. de; CENTURION, J.F.; FALQUETO, R.J.; MARTINS, A.L. da S. Qualidade física de um Latossolo Vermelho submetido a sistemas de manejo avaliado pelo índice S. Revista Brasileira de Ciência do Solo, v.35, p.87-95, 2011.

REICHERT, J.M.; SUZUKI, L.E.A.S.; REINERT, D.J.; HORN, R.; HÅKANSSON, I. Reference bulk density and critical degreeof-compactness for no-till crop production in subtropical highly weathered soils. Soil and Tillage Research, v.102, p.242-254, 2009. DOI: 10.1016/j.still.2008.07.002.

ROSA, C.M. da; CASTILHOS, R.M.V.; PAULETTO, E.A.; PILLON, C.N.; LEAL, O. dos A. Conteúdo de carbono orgânico em Planossolo Háplico sob sistemas de manejo do arroz irrigado. Revista Brasileira de Ciência do Solo, v.35, p.1769-1776, 2011. DOI: $10.1590 /$ S0100-06832011000500031.

VERNETTI JUNIOR, F. de J.; GOMES, A. da S.; SCHUCH, L.O.B. Sucessão de culturas em solos de várzea implantadas nos sistemas plantio direto e convencional. Revista Brasileira de Agrociência, v.15, p.37-42, 2009. DOI: 10.18539/cast.v15i1-4.1984.

Recebido em 31 de agosto de 2015 e aprovado em 4 de julho de 2016 